\title{
Effect of herbicide and soil amendment on growth and photosynthetic responses in olive crops
}

\author{
SUSANA REDONDO-GÓMEZ1 ${ }^{1}$, ENRIQUE MATEOS-NARANJO ${ }^{1}$, LUCÍA COX ${ }^{2}$, JUAN CORNEJO² \\ and ENRIQUE FIGUEROA ${ }^{1}$ \\ ${ }^{1}$ Departamento de Biología Vegetal y Ecología, Facultad de Biología, Universidad de Sevilla, Apartado 1095, 41080 Sevilla, Spain \\ ${ }^{2}$ Instituto de Recursos Naturales y Agrobiología (CSIC), Reina Mercedes 10, 41012 Sevilla, Spain
}

Diuron [3-(3,4-dichlorophenyl)-=1,1-dimethylurea] and simazine (6-chloro- $N^{2}, N^{4}$-diethyl-1,3,5-triazine-2,4-diamine) are soilapplied herbicides used in olive crops. The objective of this study is to investigate the combined effect of these herbicides and the amendment of soil with an organic waste (OW) from the olive oil production industry on the growth and photosynthetic apparatus of adult olive trees and to compare the results with those obtained by Redondo-Gómez et al. ${ }^{[1]}$ for two-year-old trees. For this purpose, growth rate, gas exchange and chlorophyll fluorescence parameters were measured in 38-year-old olive trees, after one and two months of soil herbicide treatment and/or OW amendment. Soil co-application of OW and herbicide increases the quantum efficiency of Photosystem II (PSII) and the assimilation of $\mathrm{CO}_{2}$ in olive trees, which led to a higher relative growth rate of the branches and leaves in length. Herbicide treatment reduced the photosynthetic efficiency in olive trees after two months of soil application, while this reduction is evident from week one in younger trees.

Keywords: Adult trees; chlorophyll fluorescence; gas exchange; herbicide; olea europaea. polarography.

\section{Introduction}

Application of herbicides to soils is an agricultural practice necessary if stable crops are to be achieved. Diuron [3-(3,4-dichlorophenyl)-=1,1-dimethylurea] and simazine (6-chloro- $N^{2}, N^{4}$-diethyl-1,3,5-triazine-2,4-diamine) are soil-applied herbicides frequently used in olive crops in Spain. These herbicides are powerful inhibitors of photosynthesis by interrupting the light-driven flow of electrons from water to Nicotinamide adenine dinucleotide phosphate (NADP). ${ }^{[2]}$ Once in the soil, adsorption onto soil particles is one of the most important processes affecting the effectiveness of applied herbicides. ${ }^{[3-5]}$ Redondo-Gómez et al. ${ }^{[1]}$ demonstrated that the addition of a residue from the olive oil production industry (solid olive-mill organic waste, OW) to soil increases herbicide soil adsorption, especially in the case of diuron, the adsorption of which is almost ten times higher in $\mathrm{OW}$-amended soil than in the unamended.

Address correspondence to Susana Redondo Gómez, Departamento de Biología Vegetal y Ecología, Facultad de Biología, Universidad de Sevilla, Spain; Phone: +34-954-557165, Fax: +34954-615780; E-mail: susana@us.es

Received February 26, 2006.
This increase in soil adsorption gives rise to a reduction in soil solute concentration, reducing the amount of herbicide available for plant uptake. In addition, in a previous study (Redondo-Gómez et al. ${ }^{[1]}$ ) we found a reduction in photosynthetic efficiency of two-year-old olive trees three weeks after herbicide treatment. This photosynthetic stress was not detected in plants amended with OW, which has been attributed to reduction in herbicide uptake.

These results have encouraged us to perform further experiments with older olive trees, since seedlings are uncertain surrogates for adult trees given ontogenetic changes in morphological and physiological characteristics. ${ }^{[6]}$ In this context, Becker et al. ${ }^{[7]}$ found that the response to fertilization was different according to the age of the oak species.

Thus, the aim of this study is to investigate the effect of a commercial herbicide, which include diuron and simazine as active ingredients, and the effect of OW soil amendment on growth and gas exchange of Olea europaea L., and to compare these results with those obtained by RedondoGómez et al. ${ }^{[1]}$ about the combined effect of these herbicides and soil addition of OW on Photosystem II Photochemistry for two-year-old olive trees. For this purpose chlorophyll fluorescence and measurements of gas exchange using infrared gas analyzers were performed. 


\section{Materials and Methods}

\section{Plant material and treatments}

The experiment was conducted in an olive orchard at "La Hampa," an experimental farm of the Spanish Council of Scientific Research (CSIC) $15 \mathrm{~km}$ south of Seville, $\left(37^{\circ} 17^{\prime}\right.$ $\mathrm{N}, 6^{\circ} 3^{\prime} \mathrm{O}$, elevation $30 \mathrm{~m}$; SW Spain). The trees were 38 years old in 2006 and were not irrigated.

The soil is a sandy loam (Xerochrept) with depth ranking from 0.9 to $2 \mathrm{~m}$. The texture is quite homogeneus with depth, with average values from the surface to the pan of $14.8 \%$ clay, $7.0 \%$ silt, $4.7 \%$ fine sand and $73.5 \%$ coarse sand ${ }^{[8]}$ The climate of the area is typically Mediterranean.

The herbicide used in this study was a commercial formulation kindly supplied by Aragonesas Agro (Spain) containing 30\% diuron and $20 \%$ simazine. The solid olive-mill organic waste (OW) used as soil amendment is a residue from the olive oil production industry. This waste was distributed around the trunk of olive trees, in a circle of $1 \mathrm{~m}$ radius at the rate of $1 \mathrm{Kg} \mathrm{m}^{-2}$. The soil around olive trees was also treated with the commercial herbicide at the rate of $31 \mathrm{ha}^{-1}(\mathrm{H})$ and with both, herbicide and $\mathrm{OW}(\mathrm{H}+\mathrm{OW})$. In the case of herbicide treatment, herbicide was added one month after the organic amendment, in May 2006. Triplicate trees for each treatment $(\mathrm{OW}, \mathrm{H}$ and $\mathrm{H}+\mathrm{OW}$ ) were used, and triplicates without herbicide nor organic waste were used as controls.

\section{Growth}

At the beginning of the experiment, four secondary branches of each tree were marked using colored wires. In addition, two leaves were marked in the same way in each branch. At the beginning and the end of the experiment, measurements were taken of the height of the branches and the leaves. From these measurements, a daily length relative growth rate was calculated using the formula:

$$
\text { Relative growth rate }\left(\mathrm{cm} \mathrm{cm}^{-1} \mathrm{day}^{-1}\right)=\mathrm{X} \mathrm{L}^{-1} \mathrm{D}^{-1}
$$

where $\mathrm{X}=$ Average change in length of the marked branches and leaves per plant, $\mathrm{L}=$ initial length and $\mathrm{D}=$ duration of experiment in days.

\section{Measurement of gas exchange}

Gas exchange analysis was made using an open system (LI6400, LI-COR Inc., Lincoln, Neb., USA) after one and two months of treatment (June and July 2006). Net photosynthetic rate $(\mathrm{A})$, intercellular $\mathrm{CO}_{2}$ concentration $(\mathrm{Ci})$ and stomatal conductance to $\mathrm{CO}_{2}(\mathrm{Gs})$ were determined at an ambient $\mathrm{CO}_{2}$ concentration of $365 \mu \mathrm{mol} \mathrm{mol}^{-1}$, temperature of $25 / 28^{\circ} \mathrm{C}, 50 \pm 5 \%$ relative humidity and a photon flux density of $1000 \mu \mathrm{mol} \mathrm{m} \mathrm{m}^{-2} \mathrm{~s}^{-1}$. The values for $\mathrm{A}, \mathrm{Ci}$ and Gs were calculated using standard formulae from Von Caemmerer and Farquhar. ${ }^{[9]}$ The photosynthetic area was calculated after painting the surface of each leaf over a millimeter paper. The water-use efficiency (WUE) was calculated as the ratio between $\mathrm{A}$ and transpiration rate $[\mathrm{mmol}$ $\left(\mathrm{CO}_{2}\right.$ assimilated $) \mathrm{mol}^{-1}\left(\mathrm{H}_{2} \mathrm{O}\right.$ transpired $\left.)\right]$.

\section{Measurement of chlorophyll fluorescence}

Chlorophyll fluorescence was measured using a portable modulated fluorimeter (FMS-2, Hansatech Instrument Ltd., England) after one and two months of treatment (herbicide and/or OW) in adult leaves. Light and dark-adapted fluorescence parameters were measured at dawn (between 1 and $\left.7 \mu \mathrm{mol} \mathrm{m}^{-2} \mathrm{~s}^{-1}\right)$ and midday $\left(1700 \mu \mathrm{mol} \mathrm{m}^{-2} \mathrm{~s}^{-1}\right)$ in order to determine if herbicide, OW or the combination of both affected the sensitivity of plants to photoinhibition. ${ }^{[10]}$ Plants were dark-adapted for $30 \mathrm{~min}$, using leaf-clips designed for this purpose. The minimal fluorescence level in the dark-adapted state $\left(\mathrm{F}_{0}\right)$ was measured using a modulated pulse $\left(<0.05 \mu \mathrm{mol} \mathrm{m}{ }^{-2} \mathrm{~s}^{-1}\right.$ for $\left.1.8 \mu \mathrm{s}\right)$ too small to induce significant physiological changes in the plant. ${ }^{[10]}$ The data stored were an average taken over a $1.6 \mathrm{~s}$ period. Maximal fluorescence in this state $\left(\mathrm{F}_{\mathrm{m}}\right)$ was measured after applying a saturating actinic light pulse of $15000 \mu \mathrm{mol} \mathrm{m}^{-2} \mathrm{~s}^{-1}$ for 0.7 s. ${ }^{[1]}$ Values of the variable fluorescence $\left(F_{v}=F_{m}\right.$ - $\mathrm{F}_{0}$ ) and maximum quantum efficiency of PSII photochemistry $\left(\mathrm{F}_{\mathrm{v}} / \mathrm{F}_{\mathrm{m}}\right)$ were calculated from $\mathrm{F}_{0}$ and $\mathrm{F}_{\mathrm{m}}$. The same leaf area of each plant was used to measure lightadapted parameters. Steady state fluorescence yield $\left(\mathrm{F}_{\mathrm{s}}\right)$ was recorded after adapting plants to ambient light conditions for $30 \mathrm{~min}$. A saturating actinic light pulse of $15000 \mu \mathrm{mol}$ $\mathrm{m}^{-2} \mathrm{~s}^{-1}$ for $0.7 \mathrm{~s}$ was then used to produce the maximum fluorescence yield $\left(\mathrm{F}_{\mathrm{m}^{\prime}}\right)$ by temporarily inhibiting PSII photochemistry.

Using fluorescence parameters determined in both lightand dark-adapted states, the following were calculated: quantum efficiency of PSII $\left(\Phi\right.$ PSII $\left.=\frac{F_{m^{\prime}}-F_{s}}{F_{m^{\prime}}}\right) ;{ }^{[12]}$ photochemical quenching $\left(\mathrm{qP}=\frac{F_{m^{\prime}}-F_{s}}{F_{m^{\prime}}-F_{0}}\right)$, and non-photochemical quenching $\left(\mathrm{NPQ}=\frac{F_{m}-F_{m^{\prime}}}{F_{m^{\prime}}}\right){ }^{[10]}$

Statistical analysis was carried out using Statistica v. 6.0 (Statsoft Inc., Tulsa, USA). Data was analyzed using analysis of variance (F-test). Significant test results were followed by the Tukey test for identification of important contrasts. ${ }^{[13]}$ Differences between timescale measurements of one and two months, and fluorescence at dawn and midday were compared by the Student test (t-test).

\section{Results and Discussion}

\section{Growth}

Maximum relative growth rate of the branches in length were recorded for $\mathrm{H}+\mathrm{OW}$ treatment, although significant differences were found only between $\mathrm{H}$ and $\mathrm{H}+$ OW treatments [analysis of variance (ANOVA, $\mathrm{P}<0.05$; 


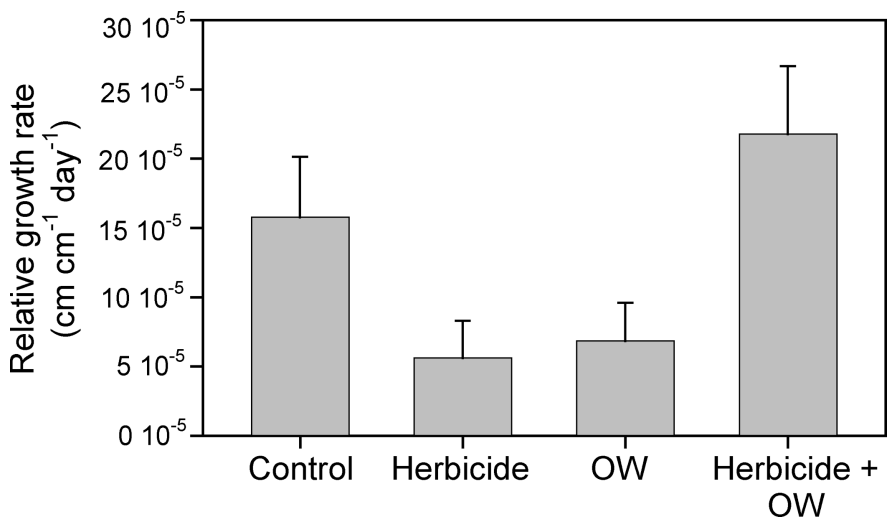

Fig. 1. Relative length growth rate of marked secondary branches of Olea europaea treated with herbicide $(\mathrm{H})$, solid olive-mill organic waste $(\mathrm{OW})$ and both of them $(\mathrm{H}+\mathrm{OW})$ for two months.

Fig. 1)]. Herbicide treatment rendered the lower growth rate of branches, which can be due to stress. Brito et al. ${ }^{[14]}$ recorded that growth of shoots of $O$. europaea ssp. maderensis was reduced under stress and Redondo-Gómez et al. ${ }^{[1]}$ found that soil application of diuron and simazine reduced the efficiency of photosystem II photochemistry of twoyear-old olive trees due to chronic photoinhibition. Growth rate of the leaves was not affected by the different treatments after two months (ANOVA, $\mathrm{P}>0.05$ ), although $\mathrm{H}+\mathrm{OW}$ trees also showed higher values than the other treatments (Fig. 2).

\section{Measurement of gas exchange}

The long-term effects of different treatments on the relative growth rate of $O$. europaea is mainly mediated by variations in net photosynthetic rate. In OW and $\mathrm{H}+\mathrm{OW}$ treatments olive trees showed higher A values than the control and $\mathrm{H}$ treatments after a month (ANOVA, $\mathrm{P}<0.05$ ). Trees under $\mathrm{H}+\mathrm{OW}$ treatment recorded the highest value of net

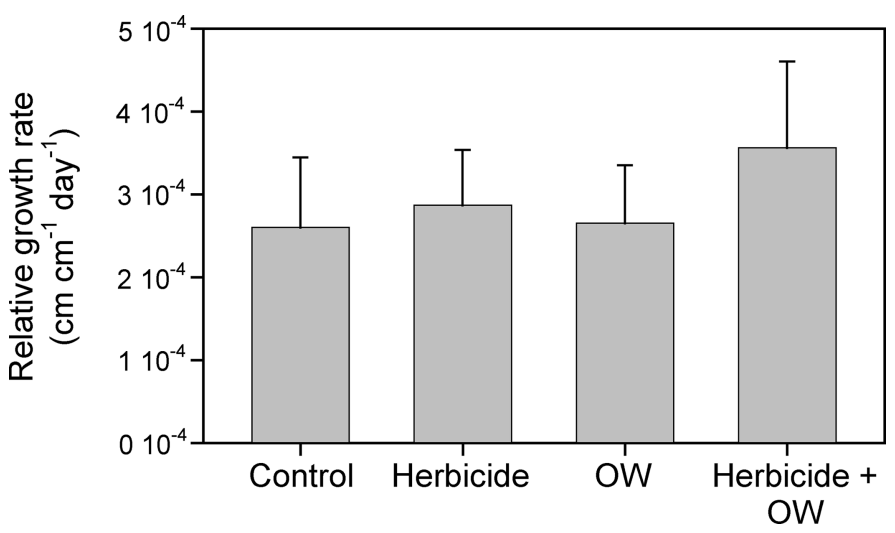

Fig. 2. Relative length growth rate of marked leaves of Olea europaea treated with herbicide $(\mathrm{H})$, solid olive-mill organic waste (OW) and both of them (H+OW) for two months. photosynthetic rate after two months (ANOVA, $\mathrm{P}<0.001$; Table 1). This is in agreement with the increase in net photosynthetic rate in winter wheat with long-term fertilization with organic manure. ${ }^{[15]}$ This higher assimilation of $\mathrm{CO}_{2}$ appeared to be due to an increase in intercellular $\mathrm{CO}_{2}$ concentration $(\mathrm{Ci})$, which can be explained by the increase in stomatal conductance $(\mathrm{Gs})$ in response to $\mathrm{H}+\mathrm{OW}$ treatment (ANOVA, $\mathrm{P}<0.01$; Table 1 ). In the case of herbicide treatment, trees showed lower values of A and Gs after one month. These values were similar to the control after two months, despite these herbicides, diuron and simazine, are known to inhibit photosynthesis of plants. ${ }^{[2,16]}$

All treatments showed similar values of water use efficiency (WUE) on timescale of up to two months, but there was a significant difference between values of WUE after one and two months (t-test, $\mathrm{P}<0.0001)$; WUE was lower at the end of the experiment (Table 1). This difference can be explained by the decrease in stomatal conductance (t-test, $\mathrm{P}<0.05)$ at the second month. In July, measurements of gas exchange were made at higher temperatures (July, $35^{\circ} \mathrm{C}$; June, $29^{\circ} \mathrm{C}$ ) without rainfalls during the experiment time, so reduction in stomatal conductance avoids the loss of water by transpiration. This agrees with Fernández et al. ${ }^{[8]}$, who showed a decrease in Gs in olive trees under deficit irrigation. At the second month of the experiment, July 2006, the measurements of gas exchange were made at higher temperature $\left(35^{\circ} \mathrm{C}\right)$ than the first month $\left(29^{\circ} \mathrm{C}\right)$. Also, the decrease in Gs explains mostly the concomitant decrease in $\mathrm{CO}_{2}$ assimilation for all treatments after two months.

\section{Measurement of chlorophyll fluorescence}

The fluorescence parameters presented in Tables 2 and 3 correspond to olive trees after one and two months of treatment, respectively. These tables show fluorescence parameters measured at midday, which indicates plants' response to light stress, and the recovery of these parameters the following day at dawn. There was a difference between values of $\mathrm{F}_{\mathrm{v}} / \mathrm{F}_{\mathrm{m}}$ at midday and dawn as a result of lower values of $\mathrm{qP}$ at midday (t-test, $\mathrm{P}<0.0001$ ). At midday, the reduction in $\mathrm{F}_{\mathrm{v}} / \mathrm{F}_{\mathrm{m}}$ values indicated that olive trees experienced photoinhibition at the higher light flux. This photoinhibition is caused by a lower proportion of open reaction centers (lower values of $\mathrm{qP}$ ) resulting from a saturation of photosynthesis by light. Also quantum efficiency of PSII ( $\Phi$ PSII) and non-photochemical quenching (NPQ) demonstrated the difference between sampling times (t-test, $\mathrm{P}<0.0001$; Tables 2 and 3) after one and two months. $\Phi$ PSII decreased as a consequence of the decrease in $\mathrm{qP}$ and the increase in NPQ, which indicates that the plants dissipated light as heat, protecting the leaf in this way from light-induced damage ${ }^{[17]}$. These results agree with those showed by Redondo-Gómez et al. ${ }^{[1]}$ for twoyear-old olive trees under the same four treatments, but do not agree with those reported by Brack and Frank ${ }^{[18]}$, which showed a simultaneous decrease in photochemical 
Table 1. Net photosynthetic rate (A), stomatal conductance (Gs), intercellular $\mathrm{CO}_{2}$ concentration $(\mathrm{Ci})$, and water use efficiency (WUE) in Olea europaea treated with herbicide $(\mathrm{H})$, solid olive-mill organic waste $(\mathrm{OW})$ and both of them $(\mathrm{H}+\mathrm{OW})$ for one and two months*

\begin{tabular}{|c|c|c|c|c|}
\hline \multirow[b]{2}{*}{ Treatments } & \multicolumn{4}{|c|}{ After one month } \\
\hline & $A\left(\mu m o l m^{-2} s^{-1}\right)$ & Gs $\left(m m o l m^{-2} s^{-1}\right)$ & $\mathrm{Ci}\left(\mathrm{\mu mol} \mathrm{mol}^{-1}\right)$ & $W U E\left(\mathrm{mmol} \mathrm{mol}^{-1}\right)$ \\
\hline Control & $15.60 \pm 0.78^{\mathrm{a}}$ & $0.22 \pm 0.02^{\mathrm{ab}}$ & $240 \pm 11.6^{\mathrm{ab}}$ & $6.59 \pm 0.57$ \\
\hline $\mathrm{H}$ & $15.13 \pm 1.04^{\mathrm{a}}$ & $0.18 \pm 0.03^{\mathrm{a}}$ & $192 \pm 25.4^{\mathrm{a}}$ & $6.59 \pm 0.70$ \\
\hline OW & $17.13 \pm 0.82^{\mathrm{ab}}$ & $0.28 \pm 0.01^{b}$ & $260 \pm 2.9^{b}$ & $6.13 \pm 0.17$ \\
\hline \multirow[t]{3}{*}{$\mathrm{H}+\mathrm{OW}$} & $18.33 \pm 0.72^{\mathrm{b}}$ & $0.28 \pm 0.03^{b}$ & $268 \pm 3.7^{\mathrm{b}}$ & $6.15 \pm 0.23$ \\
\hline & \multicolumn{4}{|c|}{ After two months } \\
\hline & $A\left(\mu m o l m^{-2} s^{-1}\right)$ & $G s\left(m m o l m^{-2} s^{-1}\right)$ & $\mathrm{Ci}\left(\mathrm{\mu mol} \mathrm{mol}^{-1}\right)$ & $W U E\left(\mathrm{mmol} \mathrm{mol}^{-1}\right)$ \\
\hline Control & $13.70 \pm 0.69^{\mathrm{a}}$ & $0.15 \pm 0.01^{\mathrm{a}}$ & $219 \pm 10.4$ & $11.69 \pm 1.03$ \\
\hline $\mathrm{H}$ & $13.83 \pm 0.67^{\mathrm{a}}$ & $0.18 \pm 0.01^{\mathrm{a}}$ & $217 \pm 4.0$ & $11.61 \pm 0.65$ \\
\hline OW & $14.15 \pm 0.76^{\mathrm{a}}$ & $0.18 \pm 0.01^{\mathrm{a}}$ & $228 \pm 5.2$ & $11.54 \pm 0.68$ \\
\hline $\mathrm{H}+\mathrm{OW}$ & $17.62 \pm 0.67^{b}$ & $0.21 \pm 0.02^{\mathrm{b}}$ & $231 \pm 8.3$ & $13.51 \pm 1.23$ \\
\hline
\end{tabular}

*Values are mean \pm standard error $(\mathrm{n}=15)$. Means within a gas exchange parameter that have a different letter are significantly different from each other (Tukey test, $\mathrm{P}<0.05$ ).

and non-photochemical quenching upon exposure to the herbicide diuron.

Redondo-Gómez et al. ${ }^{[1]}$ found that $\mathrm{F}_{\mathrm{v}} / \mathrm{F}_{\mathrm{m}}$ and ФPSII were affected by the different treatments from week one for two-year-old trees, but the present study with adult trees shows that these parameters are not affected until two months of treatment (see Tables 2 and 3) indicating that younger plants are more sensitive to herbicide treatment. The $\mathrm{F}_{\mathrm{v}} / \mathrm{F}_{\mathrm{m}}$ values at dawn recovered completely to optimal values for unstressed olives, ${ }^{[19]}$ which indicates that photoinhibition is mainly dynamic. The adult olive trees treated with herbicide recorded the lower values of $\Phi$ PSII
(0.33 and 0.81 at midday and dawn) and $F_{\mathrm{v}} / \mathrm{F}_{\mathrm{m}}$ at dawn, and the higher values of NPQ at midday, while trees treated with $\mathrm{H}+\mathrm{OW}$ showed the highest values of $\Phi$ PSII at midday (Table 3). This agrees with Redondo-Gómez et al. ${ }^{[1]}$, who showed that co-application of OW and herbicides is beneficial for olive plants, since it compensates photoinhibition induced by light stress. OW increases herbicide adsorption, reducing the amount of herbicide in the soil solution ${ }^{[4]}$ and the photoinhibitory damage that herbicides can cause. ${ }^{[17]}$ The higher assimilation of $\mathrm{CO}_{2}$ of olive trees under $\mathrm{H}+\mathrm{OW}$ treatment could be due to a higher quantum efficiency of PSII. Under laboratory conditions, there is usually a strong

Table 2. Maximum quantum efficiency of PSII photochemistry (Fv/Fm), quantum efficiency of PSII ( $\Phi$ PSII), photochemical quenching (qP) and non-photochemical quenching (NPQ), at midday and dawn in Olea europaea treated with herbicide (H), solid olive-mill organic waste $(\mathrm{OW})$ and both of them $(\mathrm{H}+\mathrm{OW})$ for one month*.

\begin{tabular}{lcccr}
\hline & \multicolumn{3}{c}{ Midday measurements } \\
\cline { 2 - 5 } Treatments & $F_{v} / F_{m}$ & $\Phi P S I I$ & $q P$ & $N P Q$ \\
\hline Control & $0.81 \pm 0.01$ & $0.46 \pm 0.03$ & $0.67 \pm 0.04$ & $0.49 \pm 0.06$ \\
H & $0.79 \pm 0.01$ & $0.42 \pm 0.02$ & $0.68 \pm 0.04$ & $0.52 \pm 0.06$ \\
OW & $0.81 \pm 0.01$ & $0.48 \pm 0.03$ & $0.73 \pm 0.02$ & $0.47 \pm 0.05$ \\
H+OW & $0.81 \pm 0.01$ & $0.49 \pm 0.02$ & $0.72 \pm 0.03$ & $0.43 \pm 0.03$
\end{tabular}

\begin{tabular}{lcccr}
\multicolumn{4}{c}{ Dawn measurements } \\
\cline { 2 - 5 } & $F_{v} / F_{m}$ & $\Phi P S I I$ & $q P$ & $N P Q$ \\
\hline Control & $0.86 \pm 0.00$ & $0.78 \pm 0.01$ & $0.94 \pm 0.01$ & $0.23 \pm 0.02$ \\
H & $0.86 \pm 0.00$ & $0.79 \pm 0.00$ & $0.95 \pm 0.00$ & $0.20 \pm 0.02$ \\
OW & $0.86 \pm 0.00$ & $0.78 \pm 0.01$ & $0.95 \pm 0.01$ & $0.21 \pm 0.02$ \\
H+OW & $0.86 \pm 0.00$ & $0.79 \pm 0.00$ & $0.95 \pm 0.00$ & $0.22 \pm 0.02$
\end{tabular}

*Values are mean \pm standard error $(\mathrm{n}=12)$. Means within a fluorescence parameter that have different letter are significantly different from each other (Tukey test, $\mathrm{P}<0.05$ ). 
Table 3. Maximum quantum efficiency of PSII photochemistry ( $\mathrm{Fv} / \mathrm{Fm})$, quantum efficiency of PSII ( $\Phi$ PSII), photochemical quenching (qP) and non-photochemical quenching (NPQ), at midday and dawn in Olea europaea treated with herbicide (H), solid olive-mill organic waste $(\mathrm{OW})$ and both of them $(\mathrm{H}+\mathrm{OW})$ for two months*.

Midday measurements

\begin{tabular}{lcccr}
\cline { 2 - 5 } Treatments & $F_{v} / F_{m}$ & $\Phi P S I I$ & $q P$ & $N P Q$ \\
\hline Control & $0.81 \pm 0.00^{\mathrm{a}}$ & $0.37 \pm 0.02^{\mathrm{a}}$ & $0.54 \pm 0.03^{\mathrm{a}}$ & $0.61 \pm 0.06^{\mathrm{a}}$ \\
H & $0.82 \pm 0.00^{\mathrm{ab}}$ & $0.33 \pm 0.01^{\mathrm{b}}$ & $0.48 \pm 0.02^{\mathrm{a}}$ & $0.59 \pm 0.05^{\mathrm{a}}$ \\
OW & $0.83 \pm 0.00^{\mathrm{b}}$ & $0.39 \pm 0.02^{\mathrm{ac}}$ & $0.52 \pm 0.03^{\mathrm{a}}$ & $0.52 \pm 0.07^{\mathrm{ab}}$ \\
H+OW & $0.82 \pm 0.00^{\mathrm{ab}}$ & $0.43 \pm 0.02^{\mathrm{d}}$ & $0.63 \pm 0.03^{\mathrm{b}}$ & $0.47 \pm 0.03^{\mathrm{b}}$
\end{tabular}

Dawn measurements

\begin{tabular}{lcccr}
\cline { 2 - 4 } & $F_{v} / F_{m}$ & $\Phi P S I I$ & $q P$ & $N P Q$ \\
\hline Control & $0.86 \pm 0.00^{\mathrm{ac}}$ & $0.82 \pm 0.00^{\mathrm{ab}}$ & $0.97 \pm 0.00$ & $0.11 \pm 0.02$ \\
H & $0.85 \pm 0.00^{\mathrm{a}}$ & $0.81 \pm 0.00^{\mathrm{a}}$ & $0.96 \pm 0.00$ & $0.11 \pm 0.01$ \\
OW & $0.87 \pm 0.00^{\mathrm{b}}$ & $0.83 \pm 0.00^{\mathrm{b}}$ & $0.97 \pm 0.00$ & $0.10 \pm 0.01$ \\
H+OW & $0.86 \pm 0.00^{\mathrm{bc}}$ & $0.82 \pm 0.00^{\mathrm{ab}}$ & $0.96 \pm 0.00$ & $0.11 \pm 0.01$ \\
\hline
\end{tabular}

*Values are mean \pm standard error $(\mathrm{n}=12)$. Means within a fluorescence parameter that have different letter are significantly different from each other (Tukey test, $\mathrm{P}<0.05$ ).

linear relationship between $\Phi$ PSII and net photosynthetic rate. ${ }^{[12,20]}$

\section{Conclusions}

This long-term experiment with adult olive trees completes the results obtained by Redondo-Gómez et a ${ }^{[1]}$ for twoyear-old trees. In adult olive trees the reduction in photosynthetic efficiency after herbicide treatment appears two months after the treatment, while this reduction is evident from week one in the case of young trees. The addition of OW to olive trees treated with herbicide increases the quantum efficiency of PSII. The higher $\Phi$ PSII of plants amended with $\mathrm{OW}$ gave rise to a higher $\mathrm{Co}_{2}$ assimilation, and consequently $\mathrm{H}+\mathrm{OW}$ treatment recorded the higher relative growth rate of the length of olive tree branches and leaves.

\section{Acknowledgments}

This work has been partially financed by research project AGL2004-05818-CO2-01. The authors are grateful to Mr. F. Fernández-Muñoz for technical assistance and to the Spanish Council of Scientific Research (CSIC) for its support (I3P Program).

\section{References}

[1] Redondo-Gómez, S.; Cox, L.; Cornejo, J. Combined effect of diuron and simazine used in olive crops and soil addition of solid olive-mill waste on photosystem II photochemistry. J. Environ. Sci. Health, Part B 2007, A42, 2007, 42, 249-254.
[2] Kearney, P.C.; Kaufman, D.D. Herbicides: Chemistry, Degradation and Mode of Action; Marcel Dekker: New York, 1975.

[3] Alexander, R.R.; Alexander, M. Bioavailability of genotoxic compounds. Environ. Sci. Technol. 2000, 34, 1589-1593.

[4] Koskinen, W.C.; Harper, S.S. The retention process: Mechanisms. In Pesticides in the Soil Environment: Processes, Impact and Modeling; Cheng, H.H., Ed.; Soil Science Society of America: Madison, Wisconsin, 1990; 51-77.

[5] Van Gestel, C.A.M.; Van Dis, W.A. The influence of soil characteristics on the toxicity of four chemicals to the earthworm Eisenia fetida andrei (Oligochaeta). Biol. Fertil. Soils 1988, 6, 262265.

[6] Kolb, T.E.; Matyssek, R. Limitations and perspectives about scaling ozone impacts in trees. Environ. Pollut. 2001, 115, 373-393.

[7] Becker, M.; Levy, G.; Lefevre, Y. Radial growth of mature pedunculate and sessile oaks in response to drainage, fertilization and weeding on acid pseudogley soils. Ann. Sci. Forest. 1996, 53, 585594.

[8] Fernández, J.E.; Díaz-Espejo, A.; Infante, J.M.; Durán, P.; Palomo, M.J.; Chamorro, V.; Girón, I.F.; Villagarcía, L. Water relations and gas exchange in olive trees under regulated deficit irrigation and partial rootzone drying. Plant Soil 2006, 284, 273291.

[9] Von Caemmerer, S.; Farquhar, G.D. Some relationships between the biochemistry of photosynthesis and the gas exchange of leaves. Planta 1981, 153, 377-387.

[10] Schreiber, U.; Schliwa, W.; Bilger, U. Continuous recording of photochemical and non-photochemical chlorophyll fluorescence quenching with a new type of modulation fluorimeter. Photosynth. Res. 1986, 10, 51-62.

[11] Bolhàr-Nordenkampf, H.R.; Öquist, G. Chlorophyll fluorescence as a tool in photosynthesis research. In Photosynthesis and Production in a Changing Environment: a Field and Laboratory Manual; Hall, D.O., Scurlock, J.M.O., Bolhàr-Nordenkampf, H.R., Leegood, R.C., Long, S.P., Eds.; Chapman and Hall: London, 1993; 193-206.

[12] Genty, B.; Briantais, J.M.; Baker, N.R. The relationship between the quantum yield of photosynthetic electron transport and quenching of chlorophyll fluorescence. Biochim. Biophys. Acta 1989, 990, 8792. 
[13] Day, R.W.; Quinn, G.P. Comparisons of treatment after an analysis of variance in Ecology. Ecol. Monogr. 1989, 59, 433-463.

[14] Brito, G.; Costa, A.; Fonseca, H.M.A.C.; Santos, C.V. Response of Olea europaea ssp. maderensis in Vitro shorts exponed to osmotic stress. Sci. Hortic. 2003, 97, 411-417.

[15] Oettmeier, W. Herbicides of photosystem II. In The Photosystems: Structure, Function and Molecular Biology; Barber, J., Ed.; Elsevier: Amsterdam, 1992; 349-408.

[16] Jiang, D.; Dai, T.; Jing, Q.; Cao, W.; Zhou, Q.; Zhao, H.; Fan, X. Effects of long-term fertilization on leaf photosynthetic characteristics and grain yield in winter wheat. Photosynthetica 2004, 42, 439 446.
[17] Maxwell, K.; Johnson, G.N. Chorophyll fluorescence-a practical guide. J. Exp. Bot. 2000, 51, 659-668.

[18] Brack, W.; Frank, H. Chlorophyll a fluorescence: a tool for the investigation of toxic effects in the photosynthetic apparatus. Ecotoxicol. Environ. Saf. 1998, 40, 34-41.

[19] Werner, C.; Correia, O.; Beyschlag, W. Characteristic patterns of chronic and dynamic photoinhibition of different functional groups in a Mediterranean ecosystem. Funct. Plant Biol. 2002, 29, 999 1011.

[20] Edwards, G.E.; Baker, N.R. Can $\mathrm{CO}_{2}$ assimilation in maize leaves be predicted accurately from chlorophyll fluorescence analysis? Photosynth. Res. 1993, 37, 89-102. 